\title{
Optimization of Electrochemical Treatment Process Conditions for Distillery Effluent Using Response Surface Methodology
}

\author{
P. Arulmathi, ${ }^{1}$ G. Elangovan, ${ }^{2}$ and A. Farjana Begum ${ }^{3}$ \\ ${ }^{1}$ Department of Civil Engineering, University College of Engineering (Anna University), Dindigul, Tamil Nadu 624622, India \\ ${ }^{2}$ Department of Civil Engineering, University College of Engineering (Anna University), Pattukkottai, Tamil Nadu 614701, India \\ ${ }^{3}$ Tiruchirappalli District Cooperative Milk Producer's Union Ltd., Trichy, Tamil Nadu 620023, India
}

Correspondence should be addressed to P. Arulmathi; arul.mathip@gmail.com

Received 6 July 2015; Revised 6 September 2015; Accepted 8 September 2015

Academic Editor: Nadjib Drouiche

Copyright (C) 2015 P. Arulmathi et al. This is an open access article distributed under the Creative Commons Attribution License, which permits unrestricted use, distribution, and reproduction in any medium, provided the original work is properly cited.

\begin{abstract}
Distillery industry is recognized as one of the most polluting industries in India with a large amount of annual effluent production. In this present study, the optimization of electrochemical treatment process variables was reported to treat the color and COD of distillery spent wash using Ti/Pt as an anode in a batch mode. Process variables such as $\mathrm{pH}$, current density, electrolysis time, and electrolyte dose were selected as operation variables and chemical oxygen demand (COD) and color removal efficiency were considered as response variable for optimization using response surface methodology. Indirect electrochemical-oxidation process variables were optimized using Box-Behnken response surface design (BBD). The results showed that electrochemical treatment process effectively removed the COD $(89.5 \%)$ and color $(95.1 \%)$ of the distillery industry spent wash under the optimum conditions: $\mathrm{pH}$ of 4.12 , current density of $25.02 \mathrm{~mA} / \mathrm{cm}^{2}$, electrolysis time of $103.27 \mathrm{~min}$, and electrolyte $(\mathrm{NaCl})$ concentration of $1.67 \mathrm{~g} / \mathrm{L}$, respectively.
\end{abstract}

\section{Introduction}

Distilleries are an important industrial sector in India where ethyl alcohol is produced from the cane sugar molasses by fermentation process. At the end of fermentation, broth containing $6-8 \%$ alcohol by volume is distilled to recover alcohol. Alcohol is separated by distillation and the residual liquor is discharged as effluent called "spent wash." Distillery spent wash contains high content of organic matter and it is generally dark brown liquid with an unbearable odor. When it is discharged without proper treatment it will lead to change in color and depletion of dissolved oxygen concentration of the receiving water stream [1].

Different treatment techniques are used to treat the distillery spent wash before its disposal on land or water environment. Several physical methods have been employed for the removal of organic matters from the effluent, but they have many disadvantages such as low removal efficiency and being expensive. Of the various techniques for the treatment of distillery spent wash, biomethanation has gained wide acceptability due to methane recovery in the anaerobic step of the treatment. It is reported that biological treatment results in $60-85 \%$ of the BOD reduction, but still substantial amount of recalcitrant organic pollutants is left behind in the effluent discharge [2]. Electrochemical treatment method (EC) is an attractive, alternative treatment process and has several advantages over conventional treatment methods such as easy automation, maximum removal efficiency, shorter treatment time, low sludge production, and reasonable operating cost.

In this electrochemical treatment process, electrooxidation methods were widely investigated. Electrooxidation is a process in which the pollutants are destroyed or converted into simpler forms like carbon dioxide and water. This oxidation process can be either direct or indirect oxidation. In the indirect oxidation process, strong oxidants like hypochlorite, chlorine, hydrogen peroxide, and hydroxyl ions are electrochemically generated at the anode [3]. All the oxidants are produced in situ and are utilized immediately. 
The mechanism of indirect electrochemical oxidation has suggested that water is electrolyzed by anodic catalysis to produce hydroxyl radicals, being shown in

$$
\begin{gathered}
M \mathrm{O}_{x}+{ }^{-} \mathrm{OH} \longrightarrow \mathrm{MO}_{x}\left({ }^{\bullet} \mathrm{OH}\right)+\mathrm{e}^{-} \\
M \mathrm{O}_{x}\left({ }^{\bullet} \mathrm{OH}\right)+D \longrightarrow x \mathrm{CO}_{2}+x \mathrm{e}^{-}+z \mathrm{H}^{+} \\
M \mathrm{O}_{x}\left({ }^{\bullet} \mathrm{OH}\right)+D \longrightarrow \frac{1}{2} \mathrm{O}_{2}+\mathrm{e}^{-}+M \mathrm{O}_{x}
\end{gathered}
$$

Meanwhile, in the presence of chloride ion, another strong oxidant of hypochlorous acid may be produced on the anode during electrolysis and will react with organic matters:

$$
\begin{aligned}
& \mathrm{H}_{2} \mathrm{O}+\mathrm{Cl}^{-} \longrightarrow \mathrm{HClO}+\mathrm{H}^{+}+2 \mathrm{e}^{-} \\
& \mathrm{HClO}+\mathrm{R} \longrightarrow \text { product }+\mathrm{Cl}^{-}
\end{aligned}
$$

where $M$ is the anode site and $D$ is the color causing organic molecule. These equations indicate that oxidation intermediates are formed which is then degraded, resulting in destruction of the organic pollutant and color treatment. Different types of electrodes for indirect electrochemical oxidation have been investigated by various researchers for the treatment of various industrial wastewaters. An electrochemicaloxidation process is influenced strongly by the nature of the anode material [4]. Titanium coated with boron doped diamond (Ti/BDD) was tested for domestic wastewater. Lead oxide coated on expanded titanium mesh $\left(\mathrm{Ti} / \mathrm{PbO}_{2}\right)$ has been widely used in EC treatment due to its easy preparation, chemical stability, and high potentials for oxygen evolution [4]. Electrochemical-oxidation methods are likely to gain a better public acceptance than the alternative methods for environmental cleanup. Optimization of EC treatment process conditions will pave the way for minimizing the operating cost with maximum treatment efficiency. Statisticbased experimental designs have proved to be more efficient than classical one-at-a-time method, which is tedious and time-consuming, do not screen multivariables, and do not inspect the complex interactions among different factors. Besides, statistical approaches provide a systematic and efficient plan for experimentation to achieve certain goals. These methods will reduce the number of experiments; in addition to that it also considers the interactions of many factors which may affect the removal efficiency during treatment process. Response surface methodology (RSM) is a statistical technique, widely used to optimize the operational variables for experiment designing, modeling, and so forth. There are various advantages in using statistical methodologies, in terms of rapid and reliable selection of process conditions, examining the effective factors, and minimizing the error in determining the effect of parameters [5]. In this study process variables of indirect electrochemical-oxidation process such as $\mathrm{pH}$, current density, electrolysis time, and electrolyte dose were optimized to remove chemical oxygen demand (COD) and color from distillery industry spent wash using BoxBehnken response surface design (BBD).
TABLE 1: Characteristics of distillery industry spent wash.

\begin{tabular}{lcc}
\hline Serial number & Characteristics of effluent & Value \\
\hline 1 & $\mathrm{pH}$ & $4.5-5$ \\
2 & Solubility in water $(\%)$ & 100 \\
3 & Colour & Dark brown \\
4 & $\mathrm{COD}\left(\mathrm{mg} \mathrm{O}_{2} / \mathrm{L}\right)$ & $100000-130000$ \\
5 & BOD $\left(\mathrm{mg} \mathrm{O}_{2} / \mathrm{L}\right)$ & $55000-65000$ \\
6 & Odour & Burnt gelatin/glucose \\
7 & Total solids & $130000-160000$ \\
8 & Total dissolved solids & $35000-45000$ \\
9 & Total volatile solids & $60000-75000$ \\
\hline
\end{tabular}

\section{Materials and Methods}

2.1. Materials. Distillery spent wash was collected from the industry near Theni District, Tamil Nadu, India. The characteristics of distillery spent wash were determined using APHA standard methods [6]. It was shown in Table 1.

2.2. Experimental Setup. The experimental setup used in this study is shown in Figure 1, which mainly consisted of a beaker of $1200 \mathrm{~mL}$ as a reactor to hold a sample of $1000 \mathrm{~mL}$. The electrodes employed were mesh type $\mathrm{Ti} / \mathrm{Pt}(10 \mathrm{~mm} \times$ $10 \mathrm{~mm})$ anode and $\mathrm{Ti}(10 \mathrm{~mm} \times 10 \mathrm{~mm})$ as cathode. The desired current density was maintained constant by means of a precision digital direct current power supply $(0-30 \mathrm{~V}$, 0-1 A). All experiments were conducted in batch mode of operation and $\mathrm{pH}$ of the spent wash was adjusted using $0.1 \mathrm{~N} \mathrm{HCl}$ or $\mathrm{NaOH}$. In each experimental run, a sample was rigorously stirred to avoid concentration gradients. The electrodes were washed with $\mathrm{HCl}$ solution $(5 \% \mathrm{~W} / \mathrm{V})$ before each run. Following each run, the electrodes were washed, dried, and used again. At the end of each batch experiment, the sample was transferred and allowed to settle down. After a settling time of $20 \mathrm{~min}$, the supernatant sample was collected to perform the analysis of COD and color.

The efficiency of the EC process was determined in terms of the COD using the following equation:

$$
R=\frac{\left(Y_{0}-Y_{1}\right)}{Y_{0}} \times 100
$$

where $R$ is the COD removal efficiency (\%), $Y_{0}$ is initial COD of the sample, and $Y_{1}$ is final COD of the sample in $\mathrm{mg} \mathrm{O}_{2} / \mathrm{L}$.

2.3. Experimental Design. In this present study, the experimental design and statistical analysis were performed according to the RSM using Design-Expert software (trial version 7, Stat-Ease). Box-Behnken response surface experimental design (BBD) was used to optimize EC process variables such as $\mathrm{pH}$, current density, electrolysis time, and electrolyte dose on the treatment of distillery industry spent wash using electrochemical method (EC). Single factor experimental analysis was used to select the range of process variables. The factors were examined at three different levels (low, basal, and high) coded $(-1,0$, and +1$)$. The actual factor levels and coded 


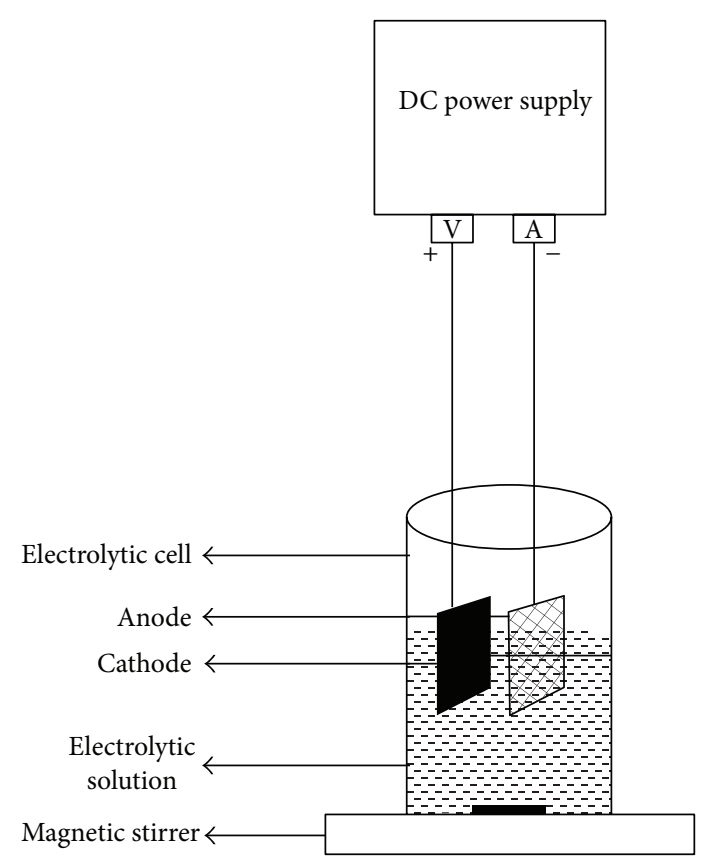

FigURE 1: Experimental setup for electrochemical method.

TABLE 2: Ranges of independent variables and their levels.

\begin{tabular}{|c|c|c|c|c|}
\hline \multirow[t]{2}{*}{ Independent variables } & \multirow{2}{*}{$\begin{array}{l}\text { Coded } \\
\text { symbol }\end{array}$} & \multicolumn{3}{|c|}{$\begin{array}{l}\text { Coded values and } \\
\text { actual factor levels }\end{array}$} \\
\hline & & -1 & 0 & +1 \\
\hline $\mathrm{pH}$ & $X_{1}$ & 1 & 3 & 5 \\
\hline $\begin{array}{l}\text { Electrolysis time } \\
\text { (min) }\end{array}$ & $X_{2}$ & 60 & 90 & 120 \\
\hline $\begin{array}{l}\text { Current density } \\
\left(\mathrm{mA} / \mathrm{cm}^{2}\right)\end{array}$ & $X_{3}$ & 20 & 35 & 50 \\
\hline $\begin{array}{l}\text { Electrolyte } \\
\text { concentration }(\mathrm{g} / \mathrm{L})\end{array}$ & $X_{4}$ & 1 & 1.5 & 2 \\
\hline
\end{tabular}

values of independent variables used for treatment of spent wash are given in Table 2.

Experiments were established based on a BBD which consists of 29 experiments with five centre points. The total number of experiments was calculated as follows:

$$
N=2 K(K-1)+C_{0},
$$

where $K$ is number of factors and number of central points is denoted by $C_{0}$.

The relationship between the operating variables and the response is described in the following empirical quadratic polynomial equation:

$$
Y=\beta_{0}+\sum_{i=1}^{k} \beta_{i} X_{i}+\sum_{i=1}^{k} \beta_{i i} X_{i}^{2}+\sum_{i=1}^{k-1} \sum_{j=2}^{k} \beta_{i j} X_{i} X_{j}
$$

where $Y$ is the response variable, $\beta_{0}$ is the constant, $\beta_{i}$ is the linear coefficient, $\beta_{i i}$ is the quadratic coefficient, and $\beta_{i j}$ is the interaction coefficients; $X_{i}$ and $X_{j}$ represent the coded independent variables. $k$ is the number of parameters; and $e_{i}$ is the error. The regression coefficients of linear, quadratic, and interaction were determined by the software, and the significance of all terms was assessed statistically using $F$ value at a probability $(P)$ of $0.001,0.01$, or 0.05 . They were further used to make statistical calculations to generate contour maps with the help of the regression model. The contour plots were generated by keeping three variables constant at the center point and varying the other two variables within the experimental range [7].

\section{Result and Discussion}

$\mathrm{BBD}$ design matrix of the independent variables in coded units (experimental design) along with experimental values of response is given in Table 3.

The results obtained from BBD experiments were analyzed by multiple regression analysis. Table 4 displays the regression coefficient and the probability $(P)$ values. A smaller $P$ value denotes greater significance of the corresponding coefficient. The effects of four independent variables including $\mathrm{pH}$, electrolysis time ( $\mathrm{min}$ ), current density $\left(\mathrm{mA} / \mathrm{cm}^{2}\right)$, and electrolyte concentration $(\mathrm{g} / \mathrm{L})$ on removal efficiency are shown in Table 4.

The effects of $\mathrm{pH}\left(X_{1}\right)$, electrolysis time $\left(X_{2}\right)$, and electrolyte concentration $\left(X_{4}\right)$ on both COD and color removal efficiency were statistically significant $(P<0.05)$, but the effect of current density on color removal efficiency is not statistically significant. Among the interaction combinations, combinations $X_{1} X_{2}, X_{2} X_{3}$, and $X_{2} X_{4}$ were found to have significant effect $(P<0.05)$ on COD removal, whereas $X_{1} X_{3}, X_{1} X_{4}$, and $X_{2} X_{4}$ have significant effect $(P<0.05)$ on color removal in distillery spent wash. In addition, the three quadratic terms $X_{1}{ }^{2}, X_{2}{ }^{2}$, and $X_{3}{ }^{2}$ have significant effects $(P<0.05)$ on both COD and color removal in spent wash, whereas $X_{4}^{2}$ have significant effect on COD removal alone and there are no effects on color removal. After using the designed experimental data and eliminating some terms, two empirical models were developed by considering only the significant terms $(P<0.05)$. The final models obtained in terms of coded factors are given in

$$
\begin{aligned}
\% \text { of COD removal }= & 86.19+6.99 \cdot X_{1}+8.94 \cdot X_{2} \\
& -5.08 \cdot X_{3}+9.21 \cdot X_{4} \\
& +6.87 \cdot\left(X_{1} X_{2}\right)+6.09 \\
& \cdot\left(X_{2} X_{3}\right)-7.83 \cdot\left(X_{2} X_{4}\right) \\
& -6.27 \cdot\left(X_{1}\right)^{2}-16.14 \\
& \cdot\left(X_{2}\right)^{2}-4.64 \cdot\left(X_{3}\right)^{2} \\
& -9.71 \cdot\left(X_{4}\right)^{2},
\end{aligned}
$$


TABLE 3: Experimental design, observed yields in BBD experiments in terms of percentage removal of COD and color.

\begin{tabular}{|c|c|c|c|c|c|c|}
\hline Run & $\mathrm{pH}$ & $\begin{array}{l}\text { Electrolysis time } \\
(\mathrm{min})\end{array}$ & $\begin{array}{l}\text { Current density } \\
\left(\mathrm{mA} / \mathrm{cm}^{2}\right)\end{array}$ & $\begin{array}{c}\text { Electrolyte } \\
\text { concentration } \\
(\mathrm{g} / \mathrm{L})\end{array}$ & $\begin{array}{c}\mathrm{COD} \\
\text { removal } \\
(\%)\end{array}$ & $\begin{array}{c}\text { Color } \\
\text { removal } \\
(\%)\end{array}$ \\
\hline 1 & 5 & 90 & 20 & 1.5 & 84.54 & 89.22 \\
\hline 2 & 3 & 90 & 35 & 1.5 & 85.56 & 92.18 \\
\hline 3 & 5 & 120 & 35 & 1.5 & 83.86 & 83.32 \\
\hline 4 & 5 & 90 & 35 & 1.0 & 76.52 & 86.27 \\
\hline 5 & 1 & 90 & 20 & 1.5 & 76.22 & 60.47 \\
\hline 6 & 5 & 90 & 35 & 2.0 & 87.22 & 92.33 \\
\hline 7 & 3 & 60 & 20 & 1.5 & 68.99 & 45.26 \\
\hline 8 & 3 & 60 & 35 & 1.0 & 32.15 & 37.24 \\
\hline 9 & 3 & 90 & 35 & 1.5 & 86.43 & 91.18 \\
\hline 10 & 1 & 90 & 35 & 1.0 & 48.52 & 52.33 \\
\hline 11 & 3 & 90 & 50 & 1.0 & 57.12 & 82.31 \\
\hline 12 & 3 & 60 & 50 & 1.5 & 45.96 & 50.25 \\
\hline 13 & 3 & 60 & 20 & 2.0 & 74.49 & 76.37 \\
\hline 14 & 3 & 90 & 50 & 2.0 & 84.45 & 94.42 \\
\hline 15 & 3 & 120 & 50 & 1.5 & 74.37 & 80.43 \\
\hline 16 & 1 & 60 & 35 & 1.5 & 59.91 & 35.19 \\
\hline 17 & 3 & 90 & 35 & 1.5 & 86.43 & 91.16 \\
\hline 18 & 3 & 120 & 35 & 2.0 & 69.38 & 76.42 \\
\hline 19 & 3 & 90 & 35 & 1.5 & 86.48 & 91.23 \\
\hline 20 & 3 & 90 & 35 & 1.5 & 86.75 & 91.16 \\
\hline 21 & 1 & 120 & 35 & 1.5 & 61.18 & 67.09 \\
\hline 22 & 3 & 60 & 35 & 2.0 & 61.96 & 82.89 \\
\hline 23 & 3 & 120 & 20 & 1.5 & 74.43 & 80.36 \\
\hline 24 & 3 & 90 & 20 & 1.0 & 65.76 & 71.32 \\
\hline 25 & 1 & 90 & 35 & 2.0 & 71.36 & 76.44 \\
\hline 26 & 5 & 90 & 50 & 1.5 & 73.24 & 80.21 \\
\hline 27 & 5 & 60 & 35 & 1.5 & 55.12 & 62.42 \\
\hline 28 & 3 & 120 & 35 & 1.0 & 69.49 & 76.91 \\
\hline 29 & 1 & 90 & 50 & 1.5 & 59.45 & 70.54 \\
\hline
\end{tabular}

\% color removal $=91.22+10.98 \cdot X_{1}+12.47 \cdot X_{2}$

$$
\begin{aligned}
& +9.52 \cdot X_{4}-2.75 \cdot\left(X_{1} X_{2}\right) \\
& -4.77 \cdot\left(X_{1} X_{3}\right)-4.5 \\
& \cdot\left(X_{1} X_{4}\right)-11.95 \cdot\left(X_{2} X_{4}\right) \\
& -10.82 \cdot\left(X_{1}\right)^{2}-20.37 \\
& \cdot\left(X_{2}\right)^{2}-4.94 \cdot\left(X_{3}\right)^{2} .
\end{aligned}
$$

The regression model was further evaluated using analysis of variance (ANOVA), and the results are shown in Table 5. The low probability value demonstrates that the model is highly significant. The goodness of fit of the model was further checked using the determination coefficient $\left(R^{2}\right)$; the values are $R^{2}=95 \%$. Furthermore, the value of $R^{2}$ also indicates that the model can explain 95\% of the total variation for the COD removal and color removal efficiency to the operating parameters. To visualize the relation between the operating variables and removal efficiency, linear plots and contour maps were generated and presented using Design-Expert (version 7.0) based on the regression model.

The graphical representations of the linear effect of the variables were developed using Design-Expert (version 7.0) software. To examine $\mathrm{pH}$ effect on the treatment efficiency, $\mathrm{pH}$ ranges are varied from 1 to 5 (Figure 2). The results showed that the percentage of COD and color removals are increased with increasing $\mathrm{pH}$ up to 4.5. It indicates that acidic condition is more favorable for the treatment of distillery spent wash. In acidic conditions, hypochlorous acid was the major compound in the solution. Therefore higher rate of decolorization and degradation in acidic condition may be due to higher oxidation potential of hypochlorous acid. Above $\mathrm{pH} 5$, the rate of reaction was lowest. This result can be 
TABLE 4: Regression coefficients obtained by the response surface model.

\begin{tabular}{|c|c|c|c|c|}
\hline \multirow{2}{*}{ Term constant } & \multicolumn{2}{|c|}{ COD reduction (\%) } & \multicolumn{2}{|c|}{ Color reduction (\%) } \\
\hline & Regression coefficient & $P$ value & Regression coefficient & $P$ value \\
\hline Intercept & 86.19 & $<0.0001$ & 91.01 & $<0.0001$ \\
\hline$X_{1}$ & 6.99 & $<0.0001$ & 10.97 & $<0.0001$ \\
\hline$X_{2}$ & 8.94 & $<0.0001$ & 12.47 & $<0.0001$ \\
\hline$X_{3}$ & -5.08 & 0.0014 & 1.12 & 0.3784 \\
\hline$X_{4}$ & 9.21 & $<0.0001$ & 9.52 & $<0.0001$ \\
\hline$X_{1} X_{1}$ & -6.27 & 0.0027 & -10.87 & $<0.0001$ \\
\hline$X_{2} X_{2}$ & -16.14 & $<0.0001$ & -20.37 & $<0.0001$ \\
\hline$X_{3} X_{3}$ & -4.64 & 0.0167 & -4.94 & 0.0092 \\
\hline$X_{4} X_{4}$ & -9.71 & $<0.0001$ & -1.93 & 0.2586 \\
\hline$X_{1} X_{2}$ & 6.87 & 0.0070 & -2.75 & 0.2083 \\
\hline$X_{1} X_{3}$ & 1.37 & 0.5894 & -4.77 & 0.0382 \\
\hline$X_{1} X_{4}$ & -3.04 & 0.1843 & -4.51 & 0.0482 \\
\hline$X_{2} X_{3}$ & -6.09 & 0.0110 & -0.81 & 0.6895 \\
\hline$X_{2} X_{4}$ & -7.83 & 0.0021 & -11.95 & $<0.0001$ \\
\hline$X_{3} X_{4}$ & 1.86 & 0.4384 & -3.66 & 0.0559 \\
\hline
\end{tabular}

TABLE 5: ANOVA for response.

\begin{tabular}{lcccc}
\hline \multirow{2}{*}{ Source } & \multicolumn{2}{c}{ COD reduction $(\%)$} & \multicolumn{2}{c}{ Color reduction $(\%)$} \\
& $F$ value & $P$ value & $F$ value & $P$ value \\
\hline Model & 20.24 & $<0.0001$ & 32.33 & $<0.0001$ \\
$A$ & 31.01 & $<0.0001$ & 83.14 & $<0.0001$ \\
$B$ & 52.20 & $<0.0001$ & 110.41 & $<0.0001$ \\
$C$ & 15.20 & 0.0014 & 0.83 & 0.3784 \\
$D$ & 51.24 & $<0.0001$ & 59.51 & $<0.0001$ \\
$A B$ & 9.98 & 0.0070 & 1.74 & 0.2083 \\
$A C$ & 0.40 & 0.5394 & 5.23 & 0.0382 \\
$A D$ & 1.95 & 0.1843 & 4.68 & 0.0482 \\
$B C$ & 8.57 & 0.0110 & 0.17 & 0.6895 \\
$B D$ & 14.17 & 0.0021 & 35.91 & $<0.0001$ \\
$C D$ & 0.64 & 0.4384 & 2.68 & 0.0559 \\
$A^{2}$ & 13.26 & 0.0027 & 42.92 & $<0.0001$ \\
$B^{2}$ & 87.68 & $<0.0001$ & 151.77 & $<0.0001$ \\
$C^{2}$ & 7.38 & 0.0167 & 9.10 & 0.0092 \\
$D^{2}$ & 32.36 & $<0.0001$ & 1.39 & 0.2586 \\
Lack of fit & 129.95 & 0.0001 & 121.42 & 0.0002 \\
$R^{2}$ & 0.9529 & & 0.9754 & \\
Adj- $R^{2}$ & 0.9058 & & 0.9508 & \\
\hline
\end{tabular}

attributed to undesirable side reactions such as oxidation of free chlorine to chlorate and perchlorate, reactions involving loss of hypochlorite.

Electrolysis time is an important parameter for controlling the reaction rate in electrochemical treatment process. The linear effect of electrolysis time on COD and color removal efficiency was studied during electrochemical treatment process by varying the electrolysis time from 60 to $120 \mathrm{~min}$, and the results are shown in Figure 3. From the observation, it is found that the percentage of COD and color removal was increased with increasing of electrolysis time up to $100 \mathrm{~min}[8]$.

The linear effect of current density on COD and color removal efficiency was studied during electrochemical treatment process by varying the current density from 20 to $50 \mathrm{~mA} / \mathrm{cm}^{-2}$, being shown in Figure 4. From the results, it is found that COD and color removal increase with increasing of current density. This is attributed to the higher formation of ion species, which has the strong affinity towards the organic matters present in the wastewater to be treated; thus removal efficiencies were increased [9].

The effect of another important process parameter (electrolyte concentration) on COD and color removal efficiency was studied during an electrochemical-oxidation treatment process by varying the concentration of $\mathrm{NaCl}$ from 1 to $2 \mathrm{~g} / \mathrm{L}$ (Figure 5). From the graph, it is noticed that the removal efficiency of COD and color increases with increasing electrolyte concentration. The concentration of electrolyte affected the conductivity. The conductivity was increased by the addition of sodium chloride. Chloride ions could significantly reduce the adverse effects of other anions, such as $\mathrm{HCO}^{3-}$ and $\mathrm{SO}_{4}{ }^{2-}$, that could form an insulating layer on the surface of the electrodes and increase the ohmic resistance of the electrochemical cell. The increase in the removal efficiency of COD and color may be attributed to a change in the ionic strength due to the increasing conductivity of aqueous medium [10].

The graphical representations of the interaction effect of the variables called the contour plots were developed using Design-Expert (version 7.0) software. Interaction between any two test variables was studied during electrochemical treatment process, keeping the other two variables constant at their middle level [11]. Circular or elliptical nature of the contours shows the interactions between the two independent variables being significant or not. Contour plots of the 

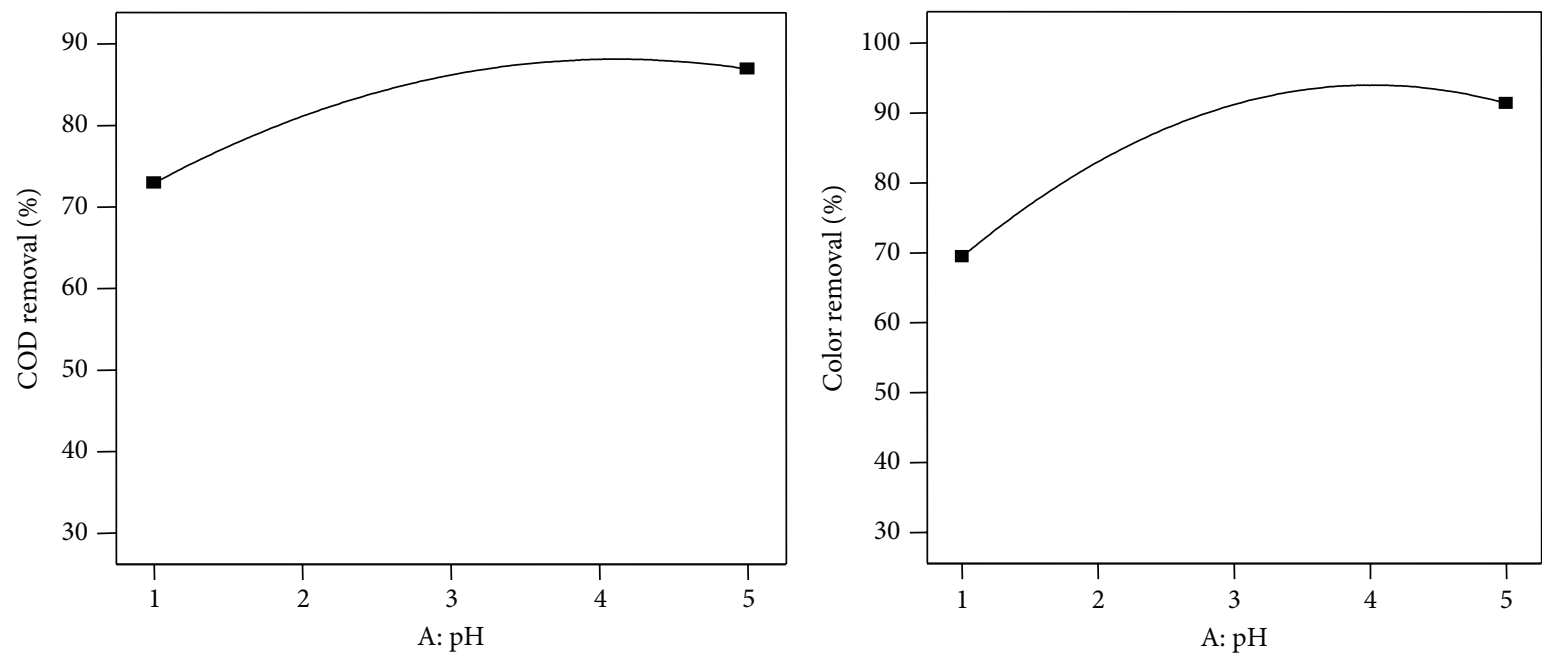

FIGURE 2: Effect of $\mathrm{pH}$ on COD and color removal.
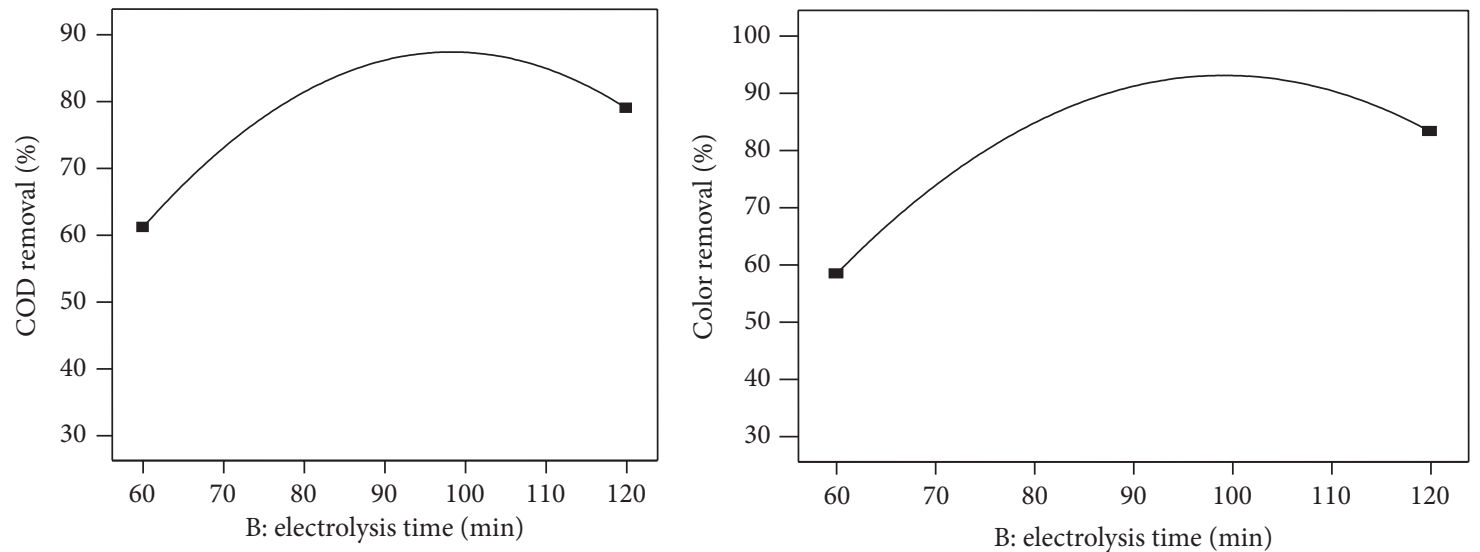

FIGURE 3: Effect of electrolysis time on COD and color removal.
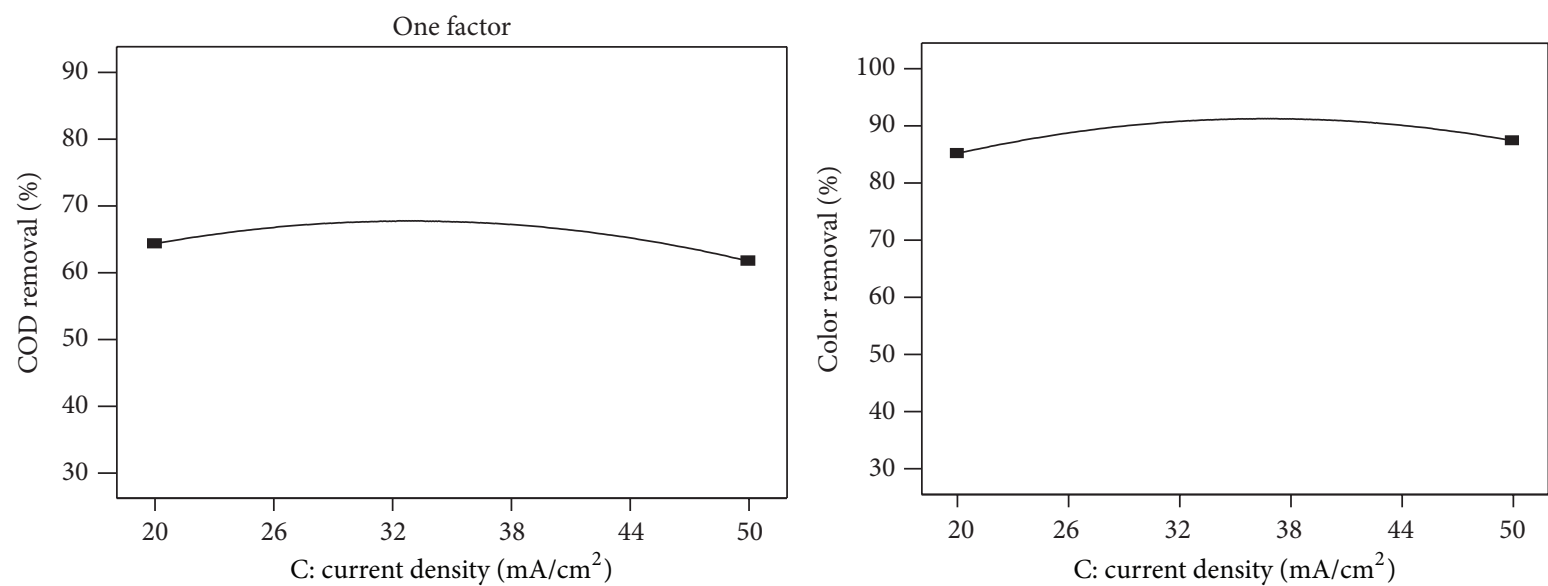

FIGURE 4: Effect of current density on COD and color removal. 

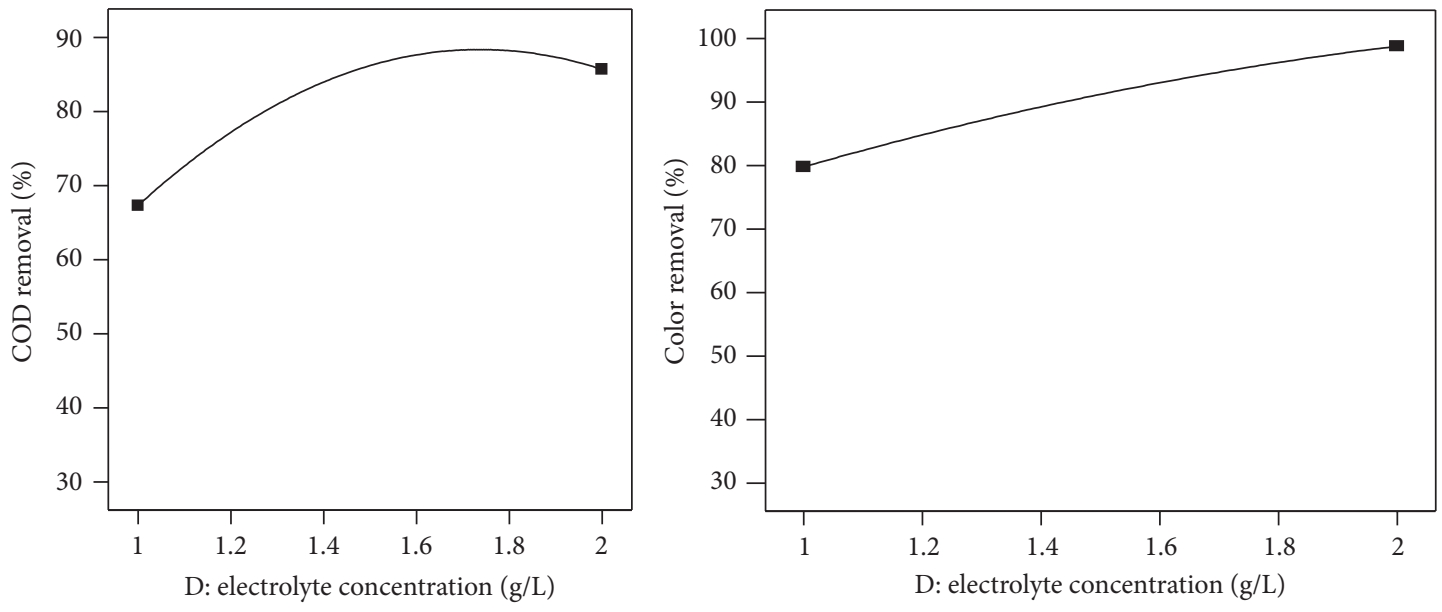

FIGURE 5: Effect of electrolyte concentration on COD and color removal.

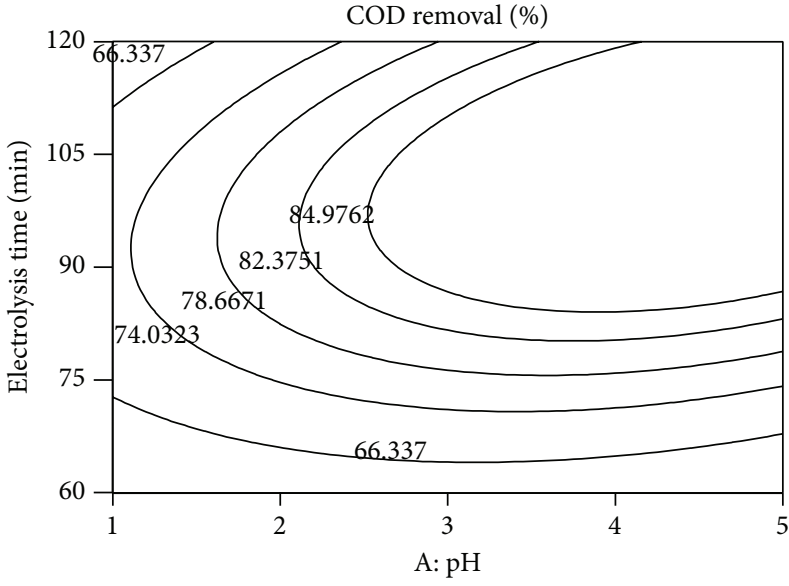

Hold values Current density: $35 \mathrm{~mA} / \mathrm{cm}^{2}$ Electrolyte concentration: $1.5 \mathrm{~g} / \mathrm{L}$

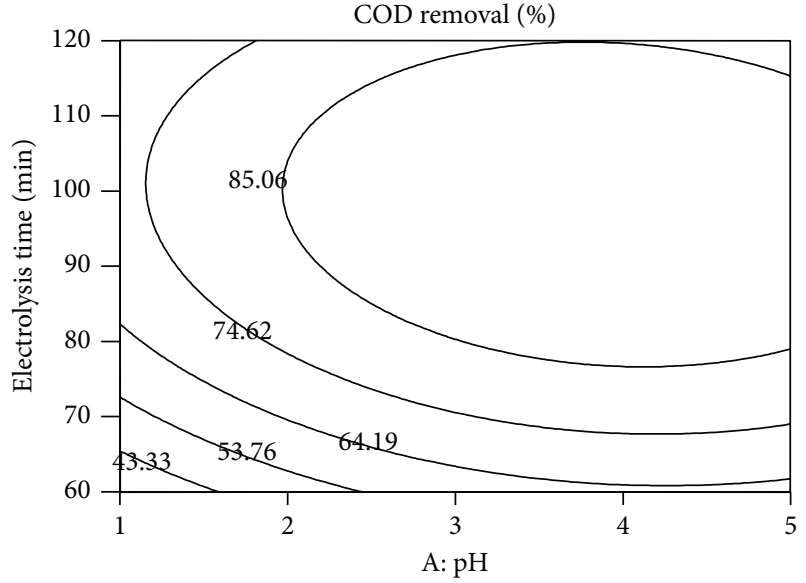

Hold values Current density: $35 \mathrm{~mA} / \mathrm{cm}^{2}$ Electrolyte concentration: $1.5 \mathrm{~g} / \mathrm{L}$

FIGURE 6: Contour plots between $\mathrm{pH}$ and electrolysis time for the responses.

interactive effect of $\mathrm{pH}$, electrolysis time ( $\mathrm{min}$ ), current density $\left(\mathrm{mA} / \mathrm{cm}^{2}\right)$, electrolyte concentration $(\mathrm{g} / \mathrm{L})$ on removal efficiency are given in Figures 6-8 showing the response.

The interaction effects of $\mathrm{pH}$ and electrolysis time (min) on COD and color reduction are shown in Figure 6, while the other variables (current density and electrolyte concentration) were fixed at central level $\left(35 \mathrm{~mA} / \mathrm{cm}^{2}\right.$ and $1.5 \mathrm{~g} / \mathrm{L}$, resp.). The elliptical shape of the contour plots between $\mathrm{pH}$ and electrolysis time (min) indicates that there is a significant interaction effect between these variables during electrochemical treatment process. Simultaneously increasing the two variables caused a linear increase in the COD and color removal efficiency. However, a decrease in the removal efficiency was observed with further increases in the two variables. The maximum values of COD and color removal were found to be $85 \%$ and $83 \%$ respectively, when $\mathrm{pH}$ and electrolysis time were found to be approximately 4 and $97 \mathrm{~min}$, respectively.
The contour map in Figure 7 shows the interaction between electrolysis time $(\mathrm{min})$ and current density $\left(\mathrm{mA} / \mathrm{cm}^{2}\right)$ on $\mathrm{COD}$ and color removal in spent wash, when the other two variables were fixed at centre level. According to Figure 7, the contours around the stationary point were circular and get elongated more along the current density axis. So a lower value of current density and electrolysis time ( $\mathrm{min}$ ) increased the percentage removal of COD and color in distillery spent wash. The results showed that the color removal efficiency increases with the increasing of current density [12].

The contour map based on two variables, electrolysis time $(\mathrm{min})$ and electrolyte concentration $(\mathrm{g} / \mathrm{L})$, is shown in Figure 8, whereas the other two variables were kept at a centre level. It can be seen that the two variables had a positive impact on both COD and color removal efficiency. At the lowest level of electrolysis time and electrolyte concentration, the removal efficiency of spent wash was found to be increase slightly at first and then decrease with 


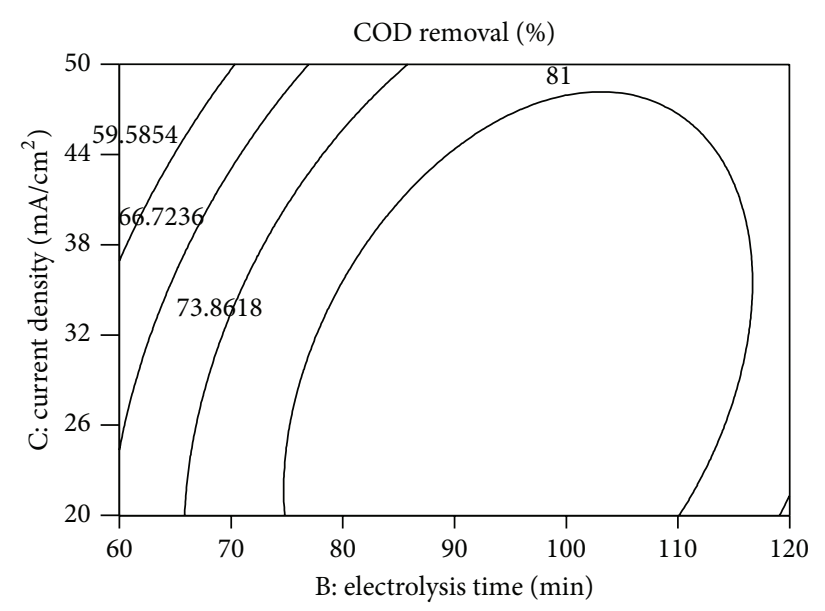

Hold values

Electrolyte concentration: $1.5 \mathrm{~g} / \mathrm{L}$ pH: 3

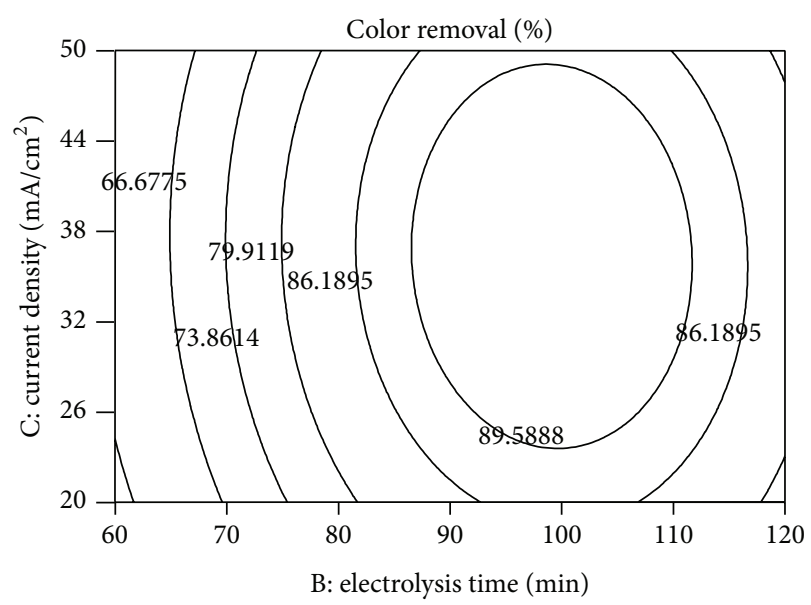

Hold values

Electrolyte concentration: $1.5 \mathrm{~g} / \mathrm{L}$ pH: 3

FIGURE 7: Contour plots between electrolysis time and current density for the responses.

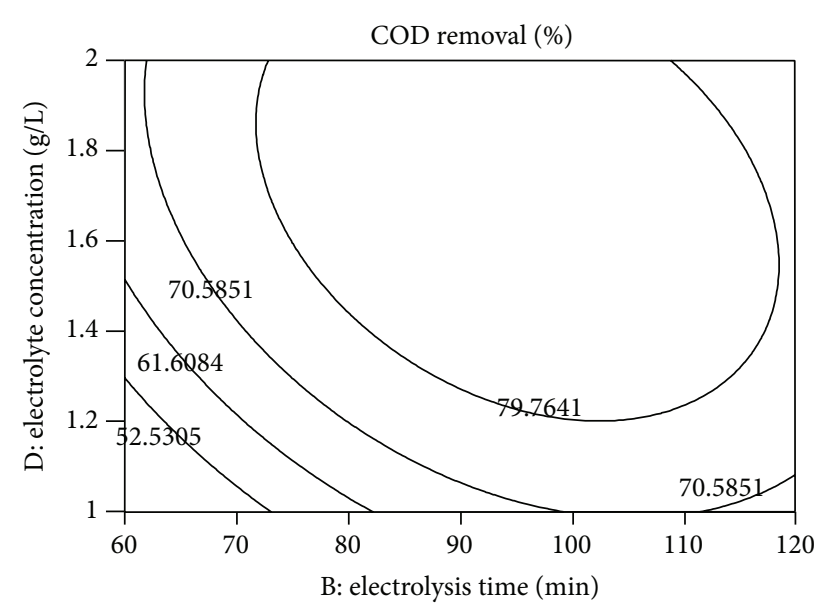

Hold values

Current density: $35 \mathrm{~mA} / \mathrm{cm}^{2}$ pH: 3

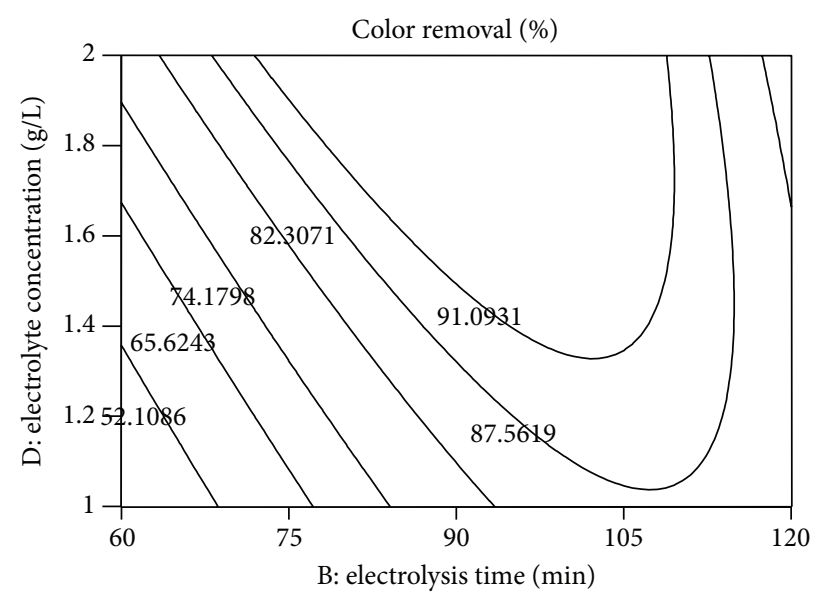

Hold values

Current density: $35 \mathrm{~mA} / \mathrm{cm}^{2}$ pH: 3

FIGURE 8: Contour plots between electrolysis time and electrolyte concentration for the responses.

continuous increasing of electrolysis time and electrolyte concentration, respectively. The maximum COD removal of spent wash was found to be $80 \%$ and Color removal of spent wash was found to be $91 \%$. The addition of $\mathrm{NaCl}$ into spent wash increases conductance and electric current of electrochemical process. Increasing solution conductivity resulted in the reduction of cell voltage that caused a decrease in electrical energy consumption. Also, solution resistance and the potential in solution decrease with the enhancement of electrolyte concentration. In this study, the removal of reactive organic compounds increased with the increasing of $\mathrm{NaCl}$ concentration. The complete removal obtained above $1.2 \mathrm{~g} / \mathrm{L} \mathrm{NaCl}$ and 90 min electrolysis time. The results of the present investigation have shown that the degradation occurred very efficiently in the presence of $\mathrm{NaCl}$ as a conductive electrolyte. It could be concluded that the degradation was faster when $\mathrm{NaCl}$ was used as electrolyte in the study. In most cases, high concentrations of supporting $\mathrm{NaCl}$ electrolyte are required for satisfactory results leading to high concentrations of hypochlorite anions and free chlorine. However, the use of $\mathrm{NaCl}$ involves the possibility of the formation of organochloride compounds, mainly due to the presence of $\mathrm{OCl}^{-}$as a possible side reaction [12].

In order to find out the optimum operating conditions to treat distillery industry spent wash using electrochemical treatment method, simultaneous optimization of the multiple responses is carried out. Here, process parameters (A-D) were selected as within range and responses $\left(Y_{1}\right.$ and $\left.Y_{2}\right)$ fixed as a maximize. Optimal operating conditions to obtain the maximum removal of $\mathrm{COD}$ and color are determined as 
follows: $\mathrm{pH}$ of 4.12 , electrolysis time of $103.27 \mathrm{~min}$, current density of $25.02 \mathrm{~mA} / \mathrm{cm}^{2}$, and electrolyte dose of $1.67 \mathrm{~g} / \mathrm{L}$, respectively. Under these optimum conditions, the COD removal efficiency and color removal efficiency were found to be $89.5 \%$ and $95.1 \%$, respectively, which are validated by conducting additional experiments under the optimal conditions. A mean value of $88.6 \%$ for COD removal and $94.65 \%$ of color removal are obtained from the experiment which are in close agreement with the predicted values obtained from numerical optimization technique. The good correlation between these observed results and predicted values indicates the reliability of BBD incorporate desirability function method and it could be effectively used to optimize the EC process parameters.

\section{Conclusion}

The electrochemical treatment of distillery spent wash was investigated with $\mathrm{Ti} / \mathrm{Pt}$ electrodes. The effects of EC process parameters such as $\mathrm{pH}$, current density, electrolyte concentration, and electrolysis time on COD and color removal were found batchwise. The best operational conditions for COD and color removal were attained in $\mathrm{pH}$ of 4.12 , electrolysis time of $103.27 \mathrm{~min}$, current density of $25.02 \mathrm{~mA} / \mathrm{cm}^{2}$, and $\mathrm{NaCl}$ dose of $1.67 \mathrm{~g} / \mathrm{L}$, respectively. During the electrochemical treatment, rapid decoloration and increased COD removal were achieved throughout the study indicating that the organic compounds and other pollutants were completely degraded into smaller, colorless organic and inorganic molecules. For the use of electrochemical treatment in industrial applications, treatment process was experimentally designed and optimized through response surface methodology, which is a promising and cost economical approach to remove organic pollutants present in distillery industry spent wash.

\section{Conflict of Interests}

The authors declare that there is no conflict of interests regarding the publication of this paper.

\section{References}

[1] R. Agarwal, S. Lata, M. Gupta, and P. Singh, "Removal of melanoidin present in distillery effluent as a major colorant: a review," Journal of Environmental Biology, vol. 31, no. 4, pp. 521528, 2010.

[2] R. Sowmeyan and G. Swaminathan, "Effluent treatment process in molasses-based distillery industries: a review," Journal of Hazardous Materials, vol. 152, no. 2, pp. 453-462, 2008.

[3] C. Thakur, V. C. Srivastava, and I. D. Mall, "Electrochemical treatment of a distillery wastewater: parametric and residue disposal study," Chemical Engineering Journal, vol. 148, no. 2-3, pp. 496-505, 2009.

[4] V. Sangeetha, V. Sivakumar, A. Sudha, and K. Kannan, "Electrochemical degradation of sago wastewater using $\mathrm{Ti} / \mathrm{PbO}_{2}$ electrode: optimisation using response surface methodology," International Journal of Electrochemical Science, vol. 10, no. 2, pp. 1506-1516, 2015.
[5] K. Ravikumar, S. Krishnan, S. Ramalingam, and K. Balu, “Optimization of process variables by the application of response surface methodology for dye removal using a novel adsorbent," Dyes and Pigments, vol. 72, no. 1, pp. 66-74, 2007.

[6] APHA, Standard Methods for the Examination of Water and Wastewater, American Public Health Association, New York, NY, USA, 2005.

[7] T. Karichappan, S. Venkatachalam, P. M. Jeganathan, and K. Sengodan, "Treatment of rice mill wastewater using continuous electrocoagulation technique: optimization and modelling," Journal of the Korean Chemical Society, vol. 57, no. 6, pp. 761768, 2013.

[8] V. Khandegar and A. K. Saroha, "Electrochemical treatment of distillery spent wash using aluminum and iron electrodes," Chinese Journal of Chemical Engineering, vol. 20, no. 3, pp. 439443, 2012.

[9] B. M. Krishna, U. N. Murthy, B. Manoj Kumar, and K. S. Lokesh, "Electrochemical pretreatment of distillery wastewater using aluminum electrode," Journal of Applied Electrochemistry, vol. 40, no. 3, pp. 663-673, 2010.

[10] K. Thirugnanasambandham, V. Sivakumar, and J. P. Maran, "Optimization of electrocoagulation process to treat biologically pretreated bagasse effluent," Journal of the Serbian Chemical Society, vol. 79, no. 5, pp. 613-626, 2014.

[11] B. K. Körbahti, "Response surface optimization of electrochemical treatment of textile dye wastewater," Journal of Hazardous Materials, vol. 145, no. 1-2, pp. 277-286, 2007.

[12] K. Thirugnanasambandham, V. Sivakumar, and J. P. Maran, "Response surface modelling and optimization of treatment of meat industry wastewater using electrochemical treatment method," Journal of the Taiwan Institute of Chemical Engineers, vol. 46, pp. 160-167, 2015. 

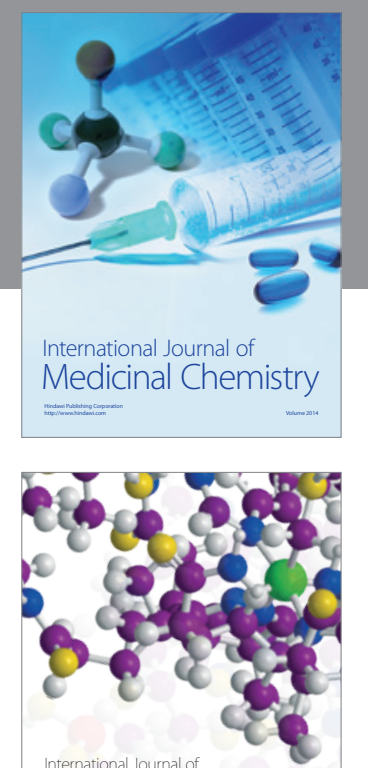

\section{Carbohydrate} Chemistry

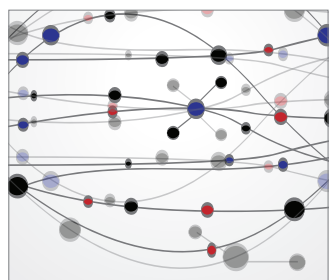

The Scientific World Journal
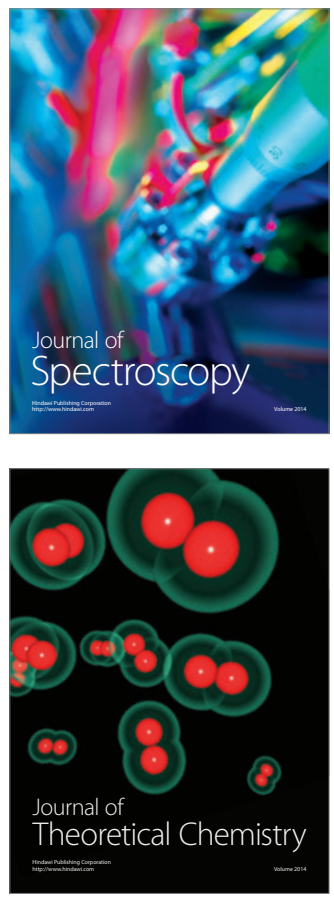
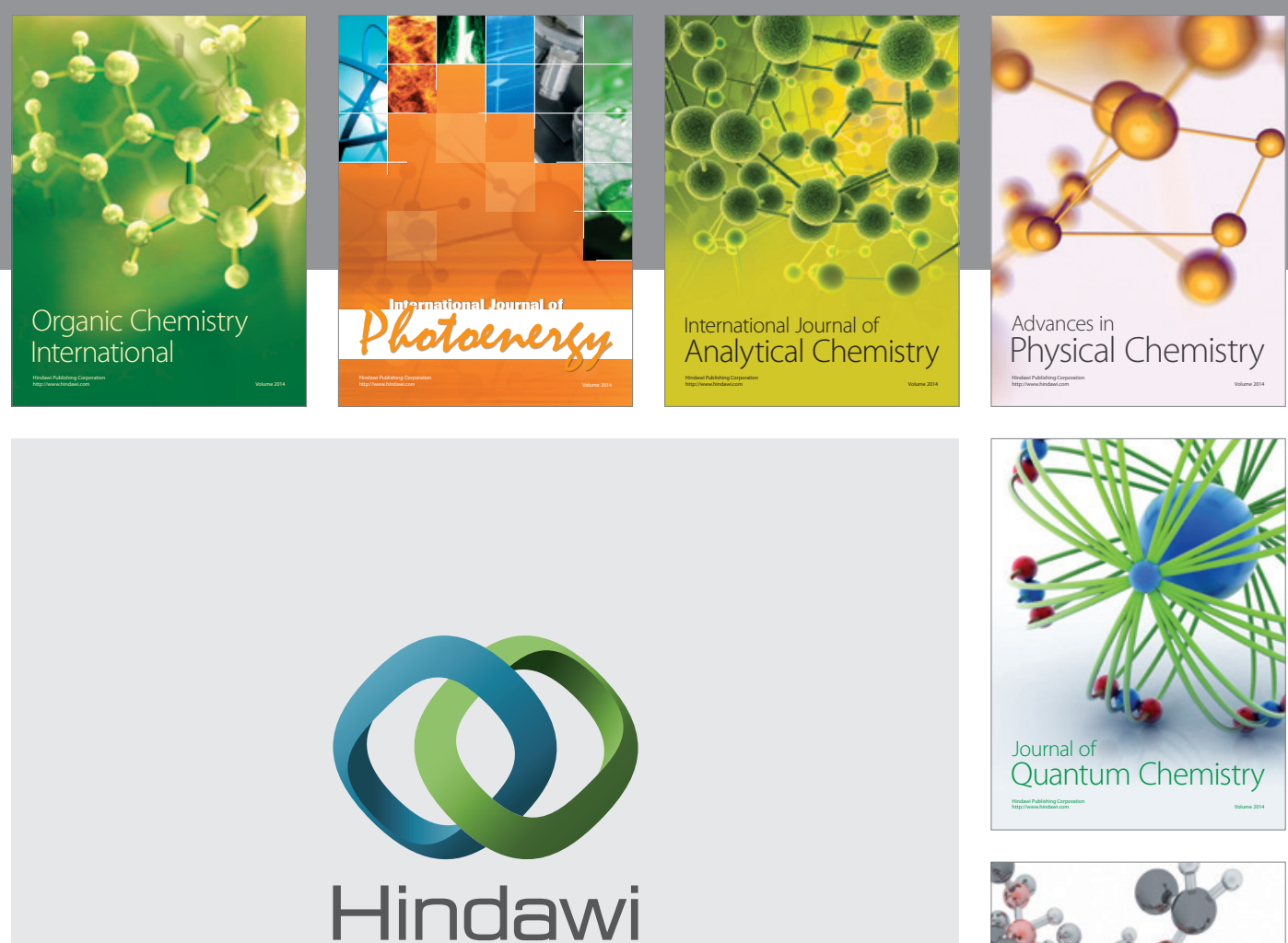

Submit your manuscripts at

http://www.hindawi.com

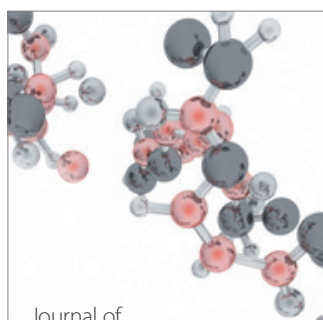

Analytical Methods

in Chemistry

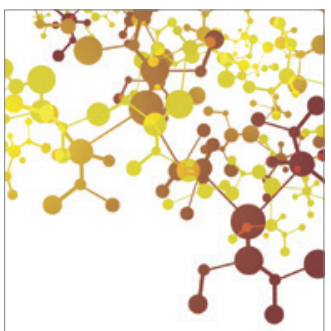

Journal of

Applied Chemistry

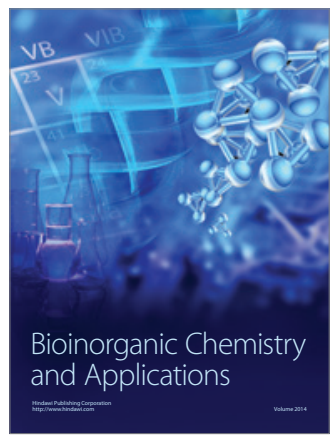

Inorganic Chemistry
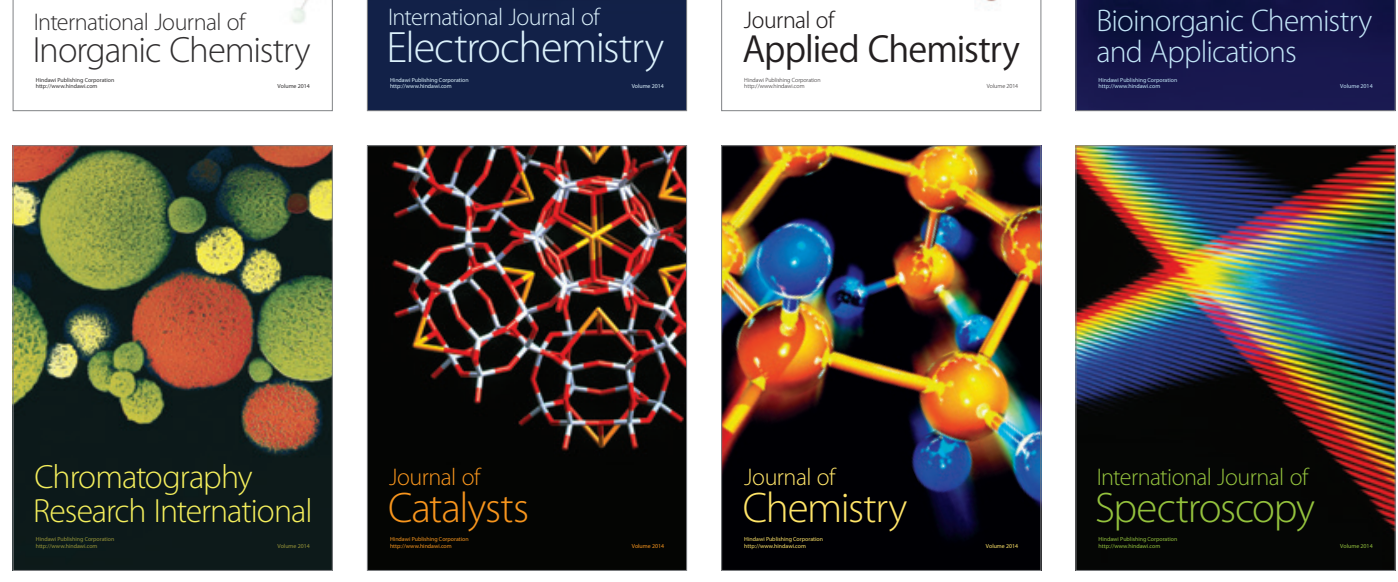